\title{
DISEÑO DE GONTENEDOR PARA EL TRATAMIENTO DE DESECHOS MÉDICOS DOMÉSTICOS FRENTE A RIESGOS SANITARIOS
}

\section{GONTAINER DESIGN FOR THE TREATMENT OF DOMESTIC MEDICAL WASTE IN THE FACE OF SANITARY RISKS}

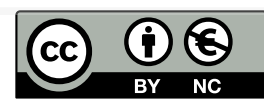

\author{
Laura Teresa Gómez-Vera \\ Universidad Autónoma del Estado de México \\ México
}

Diseñadora industrial por la Universidad Autónoma Metropolitana y, Doctora en Educación por la Escuela Libre de Ciencias Políticas y Administración Pública. Xalapa, Veracruz, México. Profesora investigadora del Centro de Investigación en Arquitectura y Diseño, Universidad Autónoma del Estado de México. Líder del Cuerpo Académico Gestión y Evaluación de Objetos de Diseño.

lagov13@gmail.com

orcid.org/0000-0002-4191-4293

\section{Irazema del Carmen Díaz Sánchez}

Universidad Autónoma del Estado de México

México

Licenciada en Diseño Industrial por la Universidad Autónoma del Estado de México. Participante en el programa de mentoría académica de la Facultad de Arquitectura y Diseño y participante en trabajos del Cuerpo Académico Gestión y Evaluación de Objetos de Diseño.

iraz12@icloud.com

orcid.org/0000-0003-1145-4748

Fecha de recepción: 01 de marzo, 2021. Aceptación: 07 de abril, 2021. 


\section{Resumen}

El desecho de materiales médicos y de curación que se utilizan en el entorno doméstico es un problema no resuelto que provoca el contagio de enfermedades diversas, pero a raíz de la pandemia SARS CoV 2 se tiene mayor riesgo en el entorno inmediato, como en aquellos en donde trabajan personas de mantenimiento y limpieza, incluyendo los recolectores de basura. En este trabajo se describe el diseño de una alternativa que facilita las funciones de triturar, desinfectar y desechar ese tipo de basura de una forma segura y responsable sin provocar efectos dañinos al ambiente. Se trabajó bajo el enfoque del Diseño Universal a fin de que su uso sea reconocible en la relación usuario-objeto-contexto mediante propiedades tales como la sencillez, la intuición, la flexibilidad, así como destacar la máxima seguridad para el usuario. Esta solución responde a ciertas especificaciones que determinan las normas mexicanas que establecen los lineamientos de seguridad en los procesos de separación, recolección, almacenamiento y disposición final de desechos médicos.

\section{Palabras clave}

Diseño de objetos, diseño universal, desechos médicos, responsabilidad social.

\section{Abstract}

The disposal of medical and wound-healing materials that are used in the domestic environment is an unsolved problem that causes the spread of various diseases, but as a result of the SARS CoV 2 pandemic, there is a greater risk both in the immediate environment, as in those where maintenance and cleaning people work, including garbage collectors. This work describes an alternative of industrial design that facilitates the functions of shredding, disinfecting, and disposing of this type of garbage safely and responsibly without causing harmful effects to the environment. A Universal Design approach was used so that its use is recognizable in the user-object-context relationship through properties such as simplicity, intuition, flexibility, as well as highlight the maximum security for the user. This solution responds to certain specifications that determine the Mexican regulations that establish the safety guidelines in the processes of separation, collection, storage, and final disposal of medical waste.

\section{Keywords}

Object design, universal design, medical waste, social responsibility. 


\section{Introducción}

En este documento se presenta una alternativa de diseño industrial que surge de la investigación que se llevó a cabo a fin de analizar y dar respuesta al problema que presenta el inadecuado manejo y desecho de utensilios médicos y de curación en el entorno de viviendas particulares, hospicios, albergues, dispensarios, casas de asistencia u otros espacios similares, que en adelante se denomina entorno doméstico. Este es un asunto que atañe a la responsabilidad social, en la medida que en ese conglomerado responda de acuerdo con la normatividad que para tal efecto se disponga, y se conozcan los efectos humanos y ambientales y sanitarios que provoca el mal desecho de jeringas, lancetas, mascarillas, torundas de algodón, vendas, guantes, gasas y fármacos, entre otros.

En México, el inadecuado manejo de esos desechos se debe a la falta de información para su adecuado tratamiento, junto a una regulación sanitaria precisa. Aunque estos entornos se pueden identificar, siguiendo las especificaciones de la NOM-087-SEMARNAT-SSA1-2002 para los establecimientos de nivel 1 que incluye unidades hospitalarias de una a cinco camas $^{1}$ (PFPA, 2002), no queda explícita la forma en la que el desecho final de residuos médicos domésticos sea seguro. Solo para el caso de hospitales y clínicas se identifica una regulación mediante las normas antes citada, además de la NOM-161-SEMARNAT-2011 y la NOM-005-SCT2-1994² (SCT, 1995).

El desconocimiento de las afectaciones que se derivan del mal uso de este tipo de desechos provoca que estos se tiren y se mezclen con cualquier otro tipo de basura doméstica o que incluso se depositen en el drenaje, causando altos focos de contagios y de propagación de enfermedades que se identifican desde alergias y salpullidos hasta otras más graves como hepatitis $B$ y $C$, virus de inmune deficiencia, y el actual SARS CoV 2 con alto grado de mortalidad; así lo manifiesta la Organización Mundial de la Salud (2018), quien ha calculado que alrededor de 15\% de los desechos sanitarios es material tóxico o infeccioso.

Los residuos médicos domésticos se convierten en una amenaza para todo aquel que los manipula, desde las personas que asisten al propio enfermo, hasta las personas de limpieza y mantenimiento 0 incluso aquellos que recolectan y clasifican la basura. Todo este personal corre un riesgo de salud al estar expuesto a materiales tóxicos e infecciosos. Como bien sabemos, la separación de los desechos orgánicos, inorgánicos y desechos especiales que se generan en el entorno doméstico es, a la fecha, un asunto que ha quedado al margen de soluciones y regulaciones. Bajo ese escenario se diseñó un dispositivo en el que, de forma segura, se pueden separar y destruir los utensilios médicos domésticos usados, siguiendo las especificaciones que las normas mexicanas antes citadas determinan para la regulación del manejo de desechos médicos, toda vez que los materiales peligrosos que han sido destruidos desde su presentación original, se pueden eliminar como residuos comunes.

\footnotetext{
${ }^{1}$ En esta clasificación se encuentran unidades hospitalarias de "una a cinco camas e instituciones de investigación, exceptuando centros de producción e investigación experimental en enfermedades infecciosas; laboratorios clínicos y bancos de sangre que realicen análisis de 1 a 50 muestras al día; Unidades hospitalarias psiquiátricas; y centros de toma de muestras para análisis clínicos". (SEMARNAT, 2002).

${ }^{2}$ La norma oficial mexicana NOM-087-SEMARNAT-SSA1-2002 (Protección ambiental - salud ambiental - residuos peligrosos biológico-infecciosos - clasificación y especificaciones de manejo) establece los lineamientos de seguridad en los procesos de separación, recolección, almacenamiento y disposición final de desechos. La norma oficial mexicana NOM-161-SEMARNAT-2011, "establece los criterios para clasificar a los residuos de manejo especial y determinar cuáles están sujetos a plan de manejo". (Semarnat, 2011).
} 


\section{Metodología de diseño}

El diseño del contenedor para el desecho de utensilios y materiales de uso médico se identificó bajo el concepto de seguridad, desde el cual se busca influenciar en la importancia que tiene, tanto para los individuos como para el medio ambiente, el desecho responsable de materiales tóxicos. Además, atender de mejor manera las dificultades y riesgos de contagio que el SARS CoV 2 ha impuesto con el uso constante de cubrebocas y guantes que en todo momento se deben mantener desinfectados, en caso de no ser de uso único. Asimismo, aportar una solución confiable para el desecho de medicamentos caducados. El objeto se diseñó bajo el enfoque del Diseño Universal a fin de que sean reconocibles, en la relación usuario-objeto-contexto, los requerimientos siguientes:

Uso equitativo: sin importar las capacidades del usuario, la seguridad del objeto debe proveer una manipulación confiable de manera que se minimicen los riesgos de uso y se advierta contra posibles errores y partes que requieran vigilancia.

Flexibilidad de uso: la identificación y el tiempo de dedicación que el usuario disponga debe adaptarse a sus necesidades y preferencias.

Sencillo e intuitivo: la respuesta intuitiva hacia el funcionamiento del objeto y su fácil manipulación son condiciones de uso inmediatas. La percepción de higiene es un asunto determinante en la confianza que cada sujeto tenga del objeto. Se reducen las acciones repetitivas, para evitar fatiga.

Información reconocible: las instrucciones para la comunicación e identificación del objeto responden a las capacidades sensoriales del usuario, mediante su jerarquización y simbología universal.

\section{Figuración del diseño}

El Contenedor para el Tratamiento de Desechos Médicos se compone de un sistema que integra las funciones de trituración, de desinfección y de recolección. Es un objeto que no permite que se mezclen los diferentes tipos de residuos y su manipulación no provoca riesgo alguno al usuario; no tiene aristas que puedan causar daño por rasgadura de los contenedores. Cuando el contenedor está vacío pesa alrededor de $1.200 \mathrm{gr}$. y en su máxima capacidad pesa de 1,300 a $2.0 \mathrm{~kg}$, lo cual facilita su maniobra.

Todas las piezas son de Acrilonitrilo Butadieno Estireno (ABS) fabricadas mediante un proceso de inyección de plástico. Se trata de un material rígido y resistente a la radiación, de baja absorción al agua en 24 horas (\%) 0.3-0.7, buena estabilidad dimensional y alta resistencia a la abrasión. Es resistente al impacto 200-400 J/m̊ y, tiene una densidad de $1,07 \mathrm{~g} / \mathrm{cm} \tilde{N}$. 
Figura 1. Contenedor de residuos médicos

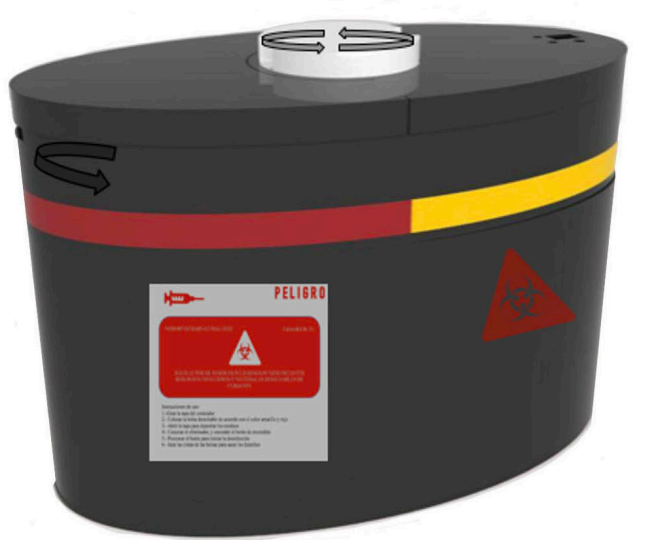

Método de desinfección de desechos médicos

La desinfección mediante luz ultravioleta (UV-C) es un proceso con el que se pueden destruir aquellos agentes que causan daños a la salud, reduciendo en su máxima capacidad la cantidad de microorganismos contaminantes en un objeto (Vignoli, 2006). Se trata de un proceso, libre de químicos, que provoca la inactivación de microorganismos de manera eficiente. Aunque los rayos UV-C, que son es un tipo rayos $X$, tienen más energía que otros, no penetran en la atmósfera y se ha demostrado que tienen una acción germicida (Sociedad Americana contra el Cáncer, 2017). Costa da Cunha (s/f) menciona que la eficacia de la desinfección con ese sistema depende de varios factores, entre ellos, la potencia de la radiación, la distancia al objeto a ser irradiado y la presencia de zonas en las que esa luz no llega directamente. Bajo esas consideraciones, es un buen método para la inactivación del SARS CoV 2 (Costa da Cunha, s/f).

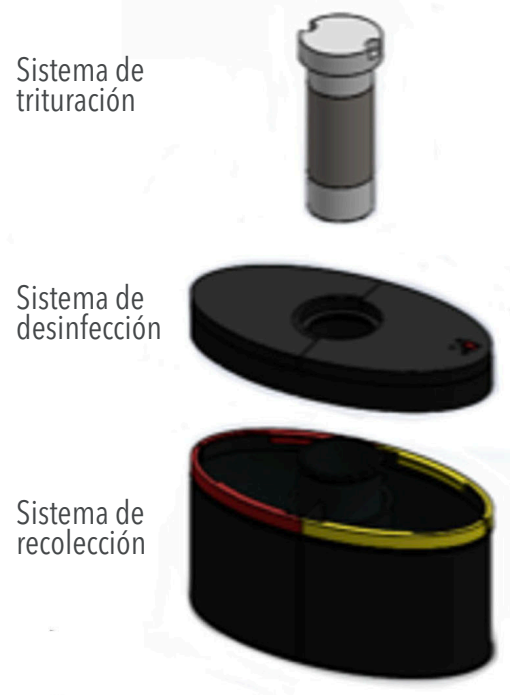

Descripción del sistema de desinfección: se realiza mediante la emisión de luz UV-C a través de un conjunto de diodos led con potencia de $9 w$ que funciona con cuatro baterías recargables de litio de 4.8 volts. El sistema se ubica en la parte interna de la carcasa superior; cuenta con ranuras de agarre y funciona como tapa de seguridad, tiene una rejilla para el soporte de las baterías y una carcasa base.

Secuencia de uso: se posiciona la tapa mediante un mecanismo de giro para ubicar el sistema de desinfección en cualquiera de los dos recipientes. Se acciona mediante dos botones que están localizados en la parte superior de la cubierta y, cuando la desinfección se ha completado se genera una alerta mediante un sonido. El proceso dura cinco minutos aproximadamente. En el exterior se muestran las instrucciones de uso: 1. conectar a la corriente eléctrica; 2. presionar interruptor hasta visualizar la luz verde; 3 . presionar el botón blanco hasta que la luz verde cambie a rojo (no se debe abrir la tapa); 4. cuando termine el proceso la luz cambiará a verde y enseguida se puede manipular la cubierta. 
Figura 2. Diseño de sistema para desinfección

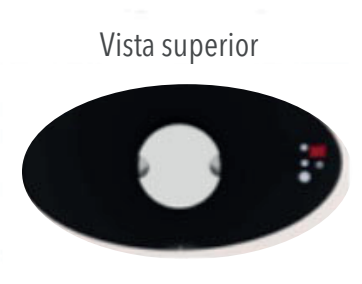

Nombre de los elementos exteriores

Representación de uso
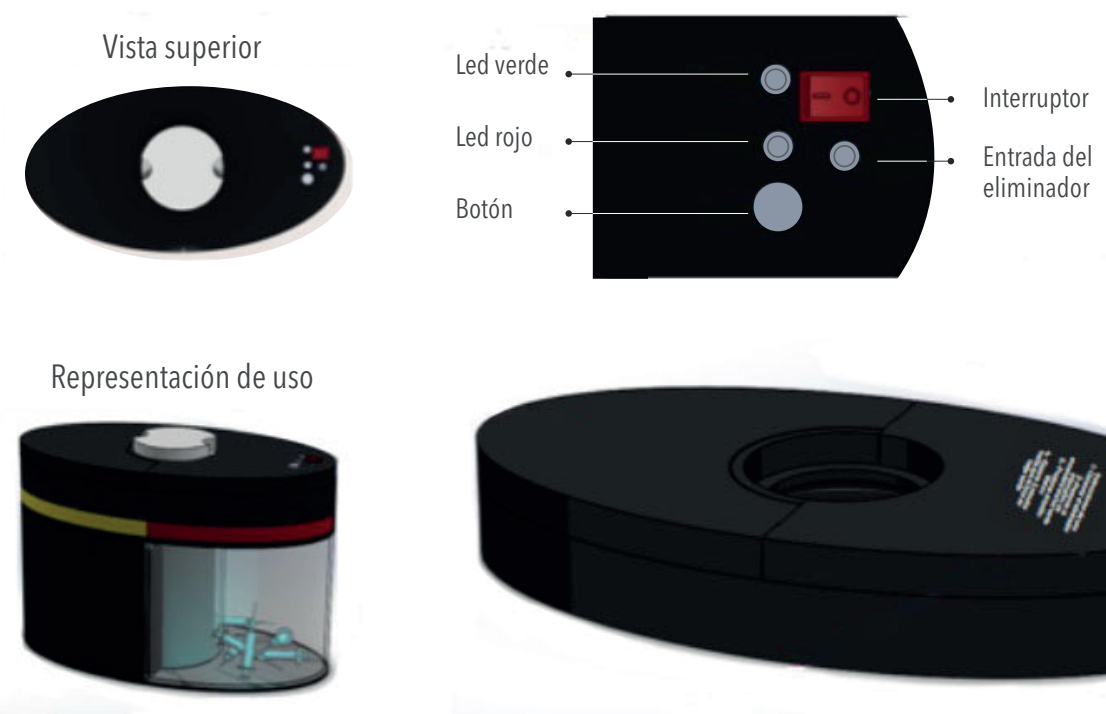

Vista posterior del sistema
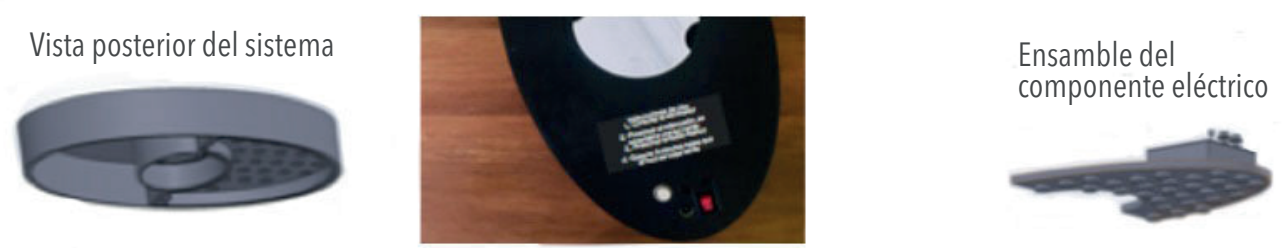

\section{Tratamiento de medicamentos caducados}

Los fármacos vencidos forman parte de los desechos químicos que se deben desechar tomando precauciones y manteniéndolos fuera de su composición original. Es muy importante evitar que estos lleguen a desagües, arroyos o fuentes de agua, así como apartarlos en su forma original del personal encargado del manejo de la basura. Aún cuando los medicamentos tienen muchas presentaciones, las pastillas, tabletas y cápsulas son las que mayor identificación pueden tener en los sitios de desecho y usarlos de forma incorrecta.

Descripción del sistema de trituración: es un proceso mecánico de fricción que permite pul- verizar las tabletas y similares. Se compone de un cilindro, una tapa y un depósito en cuyo centro se ubica un eje que, al girar en sentidos opuestos, hace que las muescas generen roce. El tamaño del dentado del anillo interior es de $4 \mathrm{~mm}$, y el anillo exterior tiene canales en forma diagonal de $3 \mathrm{~mm}$.

Secuencia de uso: es un cilindro de color blanco que se ubica en el centro el contenedor y se extrae deslizándolo por la parte superior. Luego de colocar las tabletas, la tapa y el cilindro, estas se giran en sentidos opuestos. Los residuos que caen en el contenedor se tiran en el depósito con la bolsa color amarillo. En el exterior se muestran las instrucciones de uso con flechas indicativas del giro. 
Figura 3. Diseño de sistema para trituración de pastillas

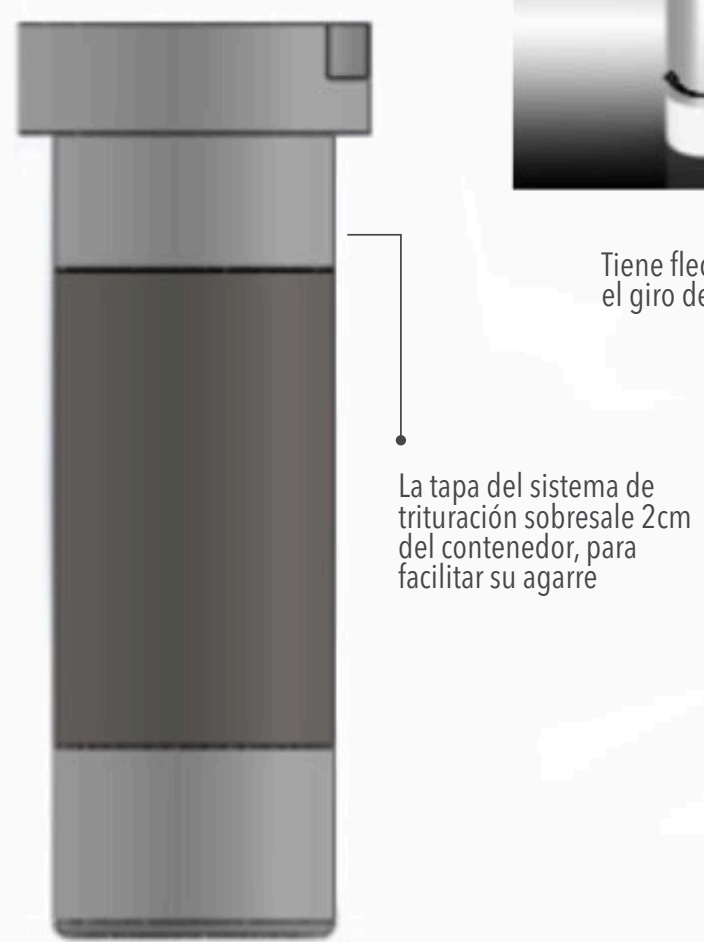

\section{Separación de desechos médicos}

Los desechos médicos que se separan en los centros de salud se distinguen según el tipo de utensilio, sus características y su estado. Se depositan en recipientes que se distinguen por color y con simbología específicas, los cuales se colocan en lugares visibles y accesibles.

La Organización Mundial de la Salud (2018) determina que en cada parte del proceso se deben manejar por separado los materiales siguientes:

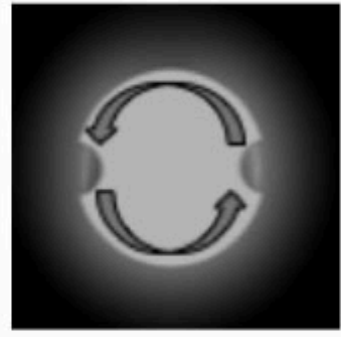

Vista de corte

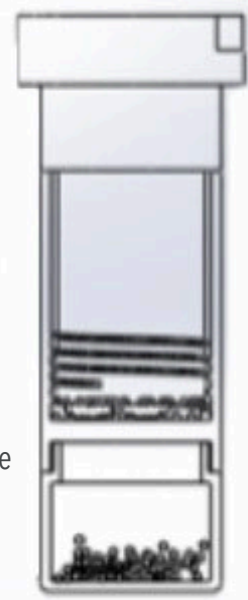

- Hisopos, vendajes e instrumental desechable - Jeringas, agujas, bisturíes, cuchillas desechables y similares

- Disolventes y desinfectantes

- Metales pesados, por ej. mercurio contenido en termómetros y pilas

- Vacunas y otros medicamentos

- Tejidos, órganos humanos y similares, y

- Material radiactivo de diagnóstico o radioterapia (OMS, 2018). 
Es necesario considerar que todos esos materiales no se deben mezclar en ninguna de las fases del desecho y tampoco pueden almacenarse durante largo tiempo desde su almacenaje inicial, hasta su tratamiento final. Los residuos que hayan sido desinfectados o tratados se pueden depositar en los transportes de basura que circula en las ciudades, mientras que los biológicos infecciosos sin tratamiento ${ }^{3}$ existen empresas recolectoras autorizadas, según se especifica en las normas NOM-161-SEMARNAT-2011 y NOM-005-SCT2/1994.

Los recipientes deben tener la resistencia necesaria a modo de que no se produzcan fugas 0 se rompan durante su manipulación, además de proveer un buen sistema de cerrado a fin de transportarlos sin riesgo alguno de derrames.

Descripción del sistema de recolección: trata de dos recipientes independientes que tienen dos arillos de color amarillo y rojo como elementos distintivos, según el tipo de residuos a contener. En la carcasa de los contenedores se encuentran instrucciones de uso y de alerta de riesgo biológico. El contenedor con el distintivo rojo es para depositar objetos punzantes, como lancetas jeringas y agujas, entre otros, y el de color amarillo para depositar desechos como algodones, cubre bocas, abatelenguas y similares.

Secuencia de uso: Se retira cada recipiente y en cada uno de ellos se coloca una bolsa desechable, amarilla o roja, según corresponda. Se regresan los contenedores a su lugar. El llenado de las bolsas no se debe sobrepasar más de $80 \%$ de su capacidad y deben cerrarse correctamente antes de depositar en la basura. Las bolsas son de polietileno de alta densidad, calibre 300 con una densidad de $1,07 \mathrm{~g} / \mathrm{cm}$. Es un material resistente a picaduras y a la luz UV-C. Las bolsas están impresas con símbolos de alerta.

${ }^{3}$ La norma NOM-005-SCT2/1994 se refiere a la "clasificación de los residuos de manejo especial" y define aquellos que están sujetos a Plan de Manejo; La norma NOM-005-SCT2/1994, trata de la información de "emergencia para el transporte terrestre de substancias, materiales y residuos peligrosos" (Semarnat, 2011). 
Figura 4. Diseño de sistema de separación de desechos

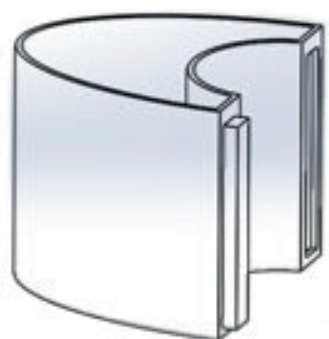

Los contenedores se mantienen unidos mediante un sistema de hembra - macho

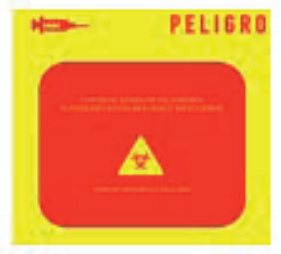

Bolsas rotuladas

Las bolsas rotuladas mencionan el tipo de desperdicios que contiene. Además las bolsas son resistentes a pinchaduras.
Los arilos de color ayudan a identificar que desecho se deposita en cada contenedor
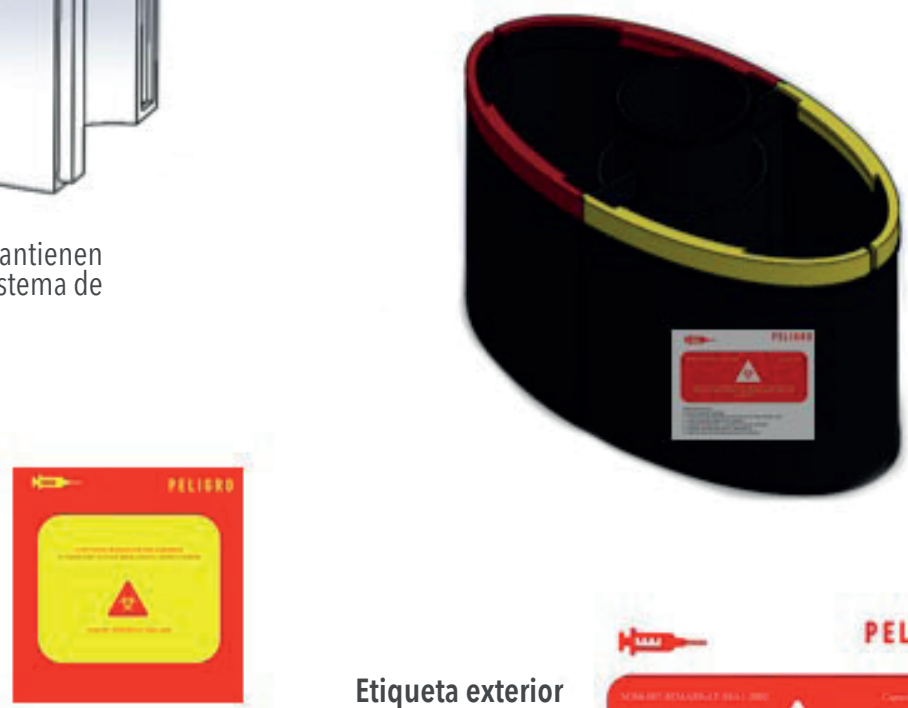

\section{Donde se}

Etiqueta exterior especifican las instrucciones de uso y tendrá el símbolo de riesgo biológico
PELIGRO

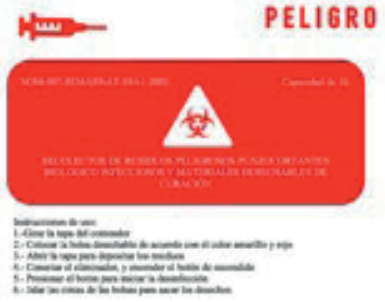

\section{Conclusiones}

La responsabilidad en crear objetos que tienen una función específica para proteger la salud e integridad de los individuos, así como contribuir con el cuidado del ambiente va más allá de cumplir con una estética que favorezca la elección del artefacto. El contenedor para el tratamiento de desechos médicos es un diseño que favorece una mayor conciencia para llevar a cabo la desinfección de todo tipo de materiales de uso médico y la desintegración de medicamentos caducados, previo a su desecho. Toda vez que el objeto se fundamenta en información conceptual y normativa que aplica al caso, este cumple cabalmente en su relación con los requerimientos que para tal efecto fueron planteados, siendo compatible en la relación usuario-objeto-contexto.

Dicho estudio realizado dio por resultado tres alternativas de solución, las cuales se evaluaron conforme a los parámetros funcionales, de uso y estructurales. El resultado de la fase de figuración del diseño fue llegar a un prototipo a fin de comprobar su eficiencia, y en adelante realizar cuantas mejoras sean necesarias hasta asegurar la completa seguridad del objeto y de los usuarios. En general se cumplió con los tres elementos que sustentan el desecho responsable de materiales médicos a través del proceso de desinfección, de trituración y de separación, así como presentar una alternativa que es original y viable funcionalmente, además de ser un objeto de fácil adquisición económicamente para su uso en el entorno doméstico. 


\section{Referencias}

Costa da Cunha, J. (s/f). Uso adecuado de lámparas germicidas. https://oftalmologos.org.ar/files/institucional/covid/uso-adecuado-de-lamparas-germicidas.pdf

OMS. (2018). Desechos de las actividades de atención sanitaria. https://www.who.int/es/newsroom/fact-sheets/detail/health-care-waste.

PFPA. (2003). Norma Oficial Mexicana NOM-087-SEMARNAT-SSA1-2002, Protección Ambiental Salud ambiental - Residuos Peligrosos Biológico-Infecciosos - Clasificación y Especificaciones de manejo. Procuraduría Federal de Protección al Ambiente-Semarnat.

SEMARNAT. (2011). Norma Oficial Mexicana NOM-161-SEMARNAT-2011, Clasificación de los Residuos de Manejo Especial - Plan de Manejo - Listado de los mismos - Procedimiento para la inclusión o exclusión a dicho listado. Semarnat

SCT. (1995). Norma Oficial Mexicana NOM-005-SCT2/1994, Información de emergencia para el transporte terrestre de substancias, materiales. Secretaria de Comunicaciones y Transportes.

Sociedad Americana Contra el Cáncer. (2017). ¿Qué es la radiación ultravioleta? https://www. cancer.org/content/cancer/es/cancer/cancer-de-piel/prevencion-y-deteccion-temprana/ que-es-la-radiacion-de-luz-ultravioleta.html

Vignoli, R. (2006). Esterilización y desinfección. Temas de Bacteriología y Virología para CEFA. Departamento de Bacteriología y Virología; Vol. 27. Facultad de Medicina. Instituto de Higiene. http://www. higiene. edu. uy/cefa/Libro2002/Cap 